\title{
Description of Sergentomyia (Parrotomyia) rectangulata sp. nov. (Diptera: Psychodidae: Phlebotominae) from southern India
}

\author{
Srinivasan Renganathan $/{ }^{+}$, Jambulingam Purushothaman \\ Vector Control Research Centre, Indian Council of Medical Research, Puducherry 605 006, India
}

Both sexes of Sergentomyia (Parrotomyia) rectangulata sp. nov. from southern India are described with illustrations. The specimens were collected in tree holes, termite mounds, cattle sheds and mud-walled, thatched roof human dwellings in rural areas. Our findings reveal similarity with Sergentomyia (Parrotomyia) modii Lewis.

Key words: Sergentomyia (Parrotomyia) rectangulata - new species - Psychodidae - India

Sergentomyia (Parrotomyia) rectangulata sp. nov., a new species of sandfly (Diptera: Psychodidae) belongs to the subgenus Parrotomyia (Theodor 1958) of the genus Sergentomyia (Franca \& Parrot 1920). In this report, male and females specimens of the new species collected from southern India are described with illustrations. Lewis (1978) described the following species under the subgenus Parrotomyia from the Orient, which includes Afghanistan, Pakistan, India, Nepal, Burma, Thailand, Vietnam, Taiwan, the Philippines, Malaysia and western Indonesia. Other species in this genus include Sergentomyia (Par.) africana asiatica (Theodor 1958), Se. (Par.) babu (Annandale 1910), Se. (Par.) insularis (Theodor 1938), Se. (Par.) baghdadis (Alder \& Theodor 1929), Se. (Par.) barraudi (Sinton 1929), Se. (Par.) bigtii (Manalang 1931), Se. (Par.) brevicaulis (Quate 1962), Se. (Par.) brevinervis (Quate \& Fairchild 1961), Se. (Par.) bukidnonis (Quate 1965), Se. (Par.) dayapensis (Manalang 1931), Se. (Par.) denticulata (Quate \& Fairchild 1961), Se. (Par.) franciscana (Quate 1965), Se. (Par.) grekovi (Khodukin 1929), Se. (Par.) himalayensis (Annandale 1910), Se. (Par.) kauli (Lewis 1972), Se. (Par.) mangana (Manalang 1930), Se. (Par.) modii (Lewis 1925), Se. (Par.) palestinensis (Adler \& Theodor 1927), Se. (Par.) queenslandi (Hill 1923), Se. (Par.) queenslandi meridionalis (Tonnoir) (Lewis \& Dyce 1976), Se. (Par.) rudnicki (Lewis 1968), Se. (Par.) shorttii (Adler \& Theodor) Theodor 1967, Se. (Par.) spinifaucis (Quate 1965), Se. (Par.) timorica (Lewis \& Dyce 1976), Se. (Par.) torrechantei (Manalang 1931) and Se. (Par.) yoshimotoi (Quate 1965). Subsequently, Artemiev (1978) added a few species to this list, such as, Se. (Par.) freetownensis (Sinton 1924), Se. (Par.) montana (Sinton 1924), Se. (Par.) sogdiana (Parrot 1929) and Se. (Par.) sumbarica (Perfiliew 1933) from Afghanistan. The species Se. (Par.) babu, Se. (Par.) insularis, Se. (Par.) baghdadis, Se. (Par.) barraudi, Se. (Par.) himalayensis, Se. (Par.) kauli, Se. (Par.) modii, Se. (Par.) shorttii, Se. africana magna, (Manalang 1930), Se. (Par.) grekovi and Se. (Par.) montana, (Lewis 1967,

+ Corresponding author: rengasrinivasan2001@yahoo.com Received 16 February 2010

Accepted 29 April 2010
1978, Kalra \& Bang 1988), Se. (Par.) shettyi Ilango 1994, Se. (Par.) santokhi (Singh \& Ipe 2005) and Se. (Par.) yencaudensis (Ilango 2004, Singh Ipe 2005) are reported to be found in India.

\section{MATERIALS AND METHODS}

Sandfly specimens were collected from the following six villages: Pillaiyarkuppam (11 ${ }^{0} 57^{\prime} 20.7^{\prime}$ 'N , 79042'30.0'E), Kalitheerthalkuppam (11055'31.6”N, 79037'46.9'E), Muth-

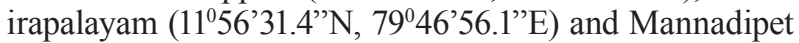
(11059'17.8'N, 79037'05.0'E) from Puducherry, Puducherry Union Territory, Avadi ( $\left.13^{0} 11^{\prime} 00.8^{\prime \prime} \mathrm{N}, 80^{\circ} 05^{\prime} 04.7^{\prime \prime} \mathrm{E}\right)$ from Tamil Nadu and Chengerla (18020'48.5'N, 79 $14^{\circ} 53.2^{\prime}$ 'E) in Andhra Pradesh. All specimens were collected during 2007-2008. The major occupation of inhabitants of these cities is agriculture and most of the households in these villages own cattle. Paddy, coconut, sugar-cane and vegetables are the major crops. Although these villages are supplied by seasonal rainfall, bore-wells are used for irrigation during the dry season. Collections of sandflies were found in human dwellings, cattle sheds, bushes, tree-holes, tree-buttresses, termite mounds and animal-burrows, during both the winter (January-March 2007-2008) and the monsoon periods (JulyOctober 2007-08), between 10 am and 12 pm, using mechanical aspirators and flashlights.

Sandflies were treated with $10 \% \mathrm{NaOH}$ and mounted on slides using Hoyer's fluid. Attempts were made to identify both sexes of the species, which apparently have the characteristic features of the subgenus Parrotomyia, using the keys for the species as described by Lewis (1967, 1978), Artemiev (1978) and Kalra and Bang (1988). Morphological identification of the species showed that males and females were sufficiently distinct from other sandflies to be treated as a new species. Morphological parameters of both male and female specimens were measured, using an Olympus binocular microscope (Model CHS, Olympus Optical Co Ltd, made in Japan) fitted with ocular and stage micrometers. All measurements are given in $\mu \mathrm{m}$. The mean value of each morphometric parameter is given. The drawings were made using the Olympus binocular microscope, with a lucida camera attached.

The terminology of the characteristics adopted is that of Lewis $(1967,1978)$ and Sinton (1929). The nomenclature follows the guidelines provided by the 
international code of zoological nomenclature (ICZN 1985). The abbreviations of taxa suggested by Marcondes (2007) were used.

\section{RESULTS}

\section{Sergentomyia (Parrotomyia) rectangulata sp. nov.}

Female - Holotype (Figs 1-3): general colour is homogeneous yellowish brown. Body size 2600. Head: frontal measurement 145. Interocular distance 165 . Interocular suture complete. Labrum 170. Labium 200. Palpi: formula 1,2 (3,4), 5. Palpomere measurements: P1 70, P2 120, P3 120, P4 140 and P5 450. Antenna: AIII 240, AIV 100, AV 100. Antennal formula III-XV, each has one ascoid, only on one side. Cibarium: yellow coloured pigment patch present, which is an inverted funnel in shape with many black spine-like particles, which are concentrated towards the proximal end and sparse towards distal end, anterior process present, sclerotised arch complete, cibarium bears a row of comb-like parallel but irregular teeth, which are 12 in number, four teeth in the centre are narrow and four teeth on each side are broad. Pharynx: lamp-glass shaped, with a bulge in the lower middle. Wings: length 1600 , width 400 . Length of principal vein sections: alpha 390 , beta 320 , gamma 280 , delta 290. R5 length $1260 \mu \mathrm{m}$. Fore leg: coxa 555, trochanter 119, femur 1125, tarsomeres: T1 655, T2 390, T3 272, T4 191, T5 158. Genitalia: cerci simple, spermathecae cylindrical in shape, length 50 , width 23 , smooth and capsulated, with secretary cells at the distal end; when viewed in sagittal plane spermatheca is rectangle in shape; individual spermathecal duct length 158 , width 8 , common spermathecal duct short and length 38 .
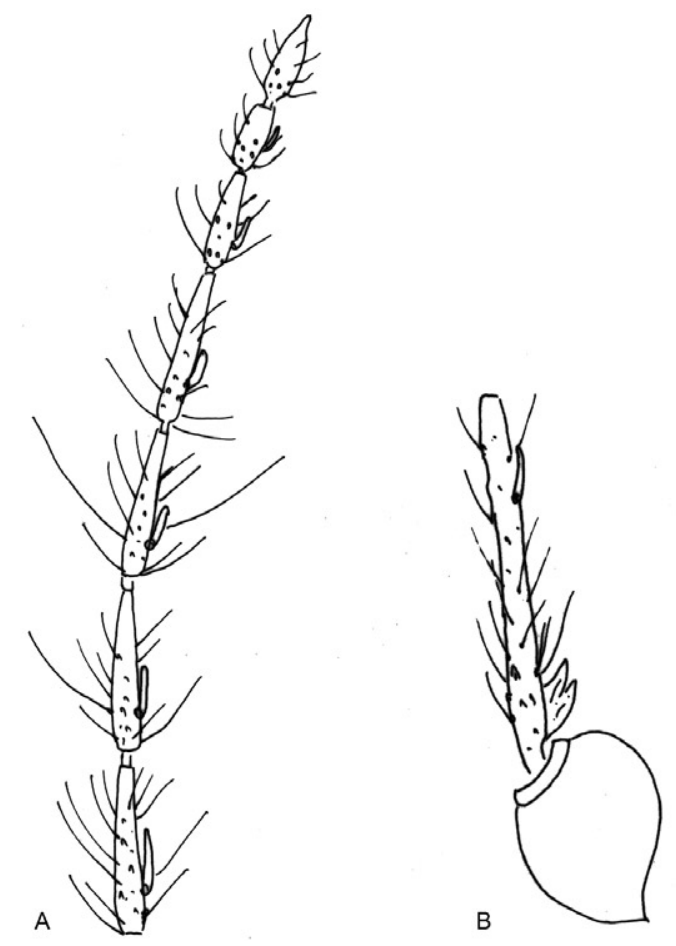

Fig. 1: female Sergentomyia (Parrotomyia) rectangulata. A: antenna terminal segment with ascoid hair; B: antenna segment III with ascoid hair.
Male - Allotype (Figs 4-6): coloured as the female. Body size $1800 \mu \mathrm{m}$. Head: frontal measure 131. Interocular distance 150. Interocular suture complete. Labrum 160, labium 190. Palpal formula: 1,2,3,4,5. Palpomeres: P1 10, P2 100, P3 103, P4 128 and P5 325. Antenna: AIII 193, A4 100, AV 103. Antennal formula: AIII-AXV each has one ascoid, only on one side. Cibarium: sclerotised arch complete. Cibarium bears a row of comb-like parallel, but irregular teeth, which are 12 in number, when viewed from ventral side. Both pigment patch and anterior process are absent. Pharynx: lamp-glass shaped and barrel shaped at posterior and gradually narrowing towards anterior end. Wings: length $1400 \mu \mathrm{m}$, width 320 $\mu \mathrm{m}$. Length of principal vein sections: alpha 360 , beta 290, gamma 260, delta 230 . R5 length 1155 . Fore leg: coxa 540, trochanter 110, femur 1100, tarsomeres: T1 645, T2 380, T3 260, T4 180, T5 150. Genitalia: as shown in Fig. 5, genital pump 55, length: genital filament 313. Ratio of genital filament/genital pump $=5.6$. Aedeagus simple, triangular and narrowing gradually, with round end. Paramere hooked with about 10 strong setae on dorsal surface. Coxite: length 260, width 75 . Style: length 115 , width 23. Style bears four spines, each measuring up to 100 in length. Two spines are terminal and remaining two are sub-terminal in position, one external superior and one external interior.
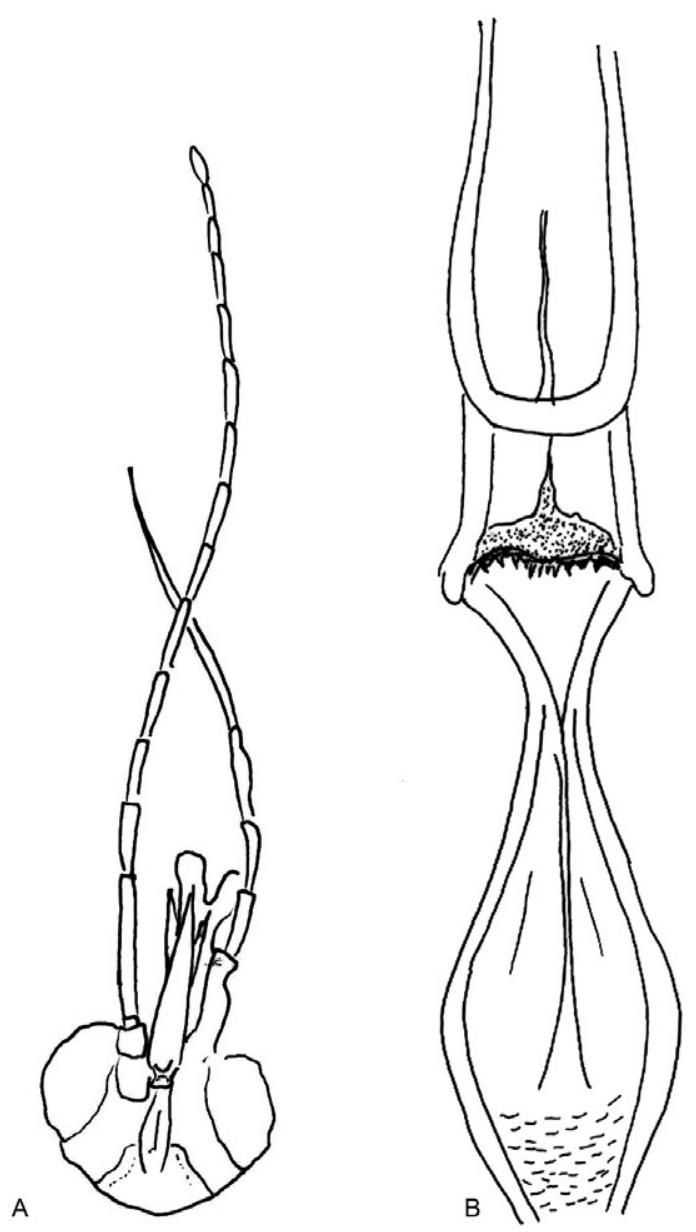

Fig. 2: female Sergentomyia (Parrotomyia) rectangulata. A: head; B: cibarium and pharynx. 

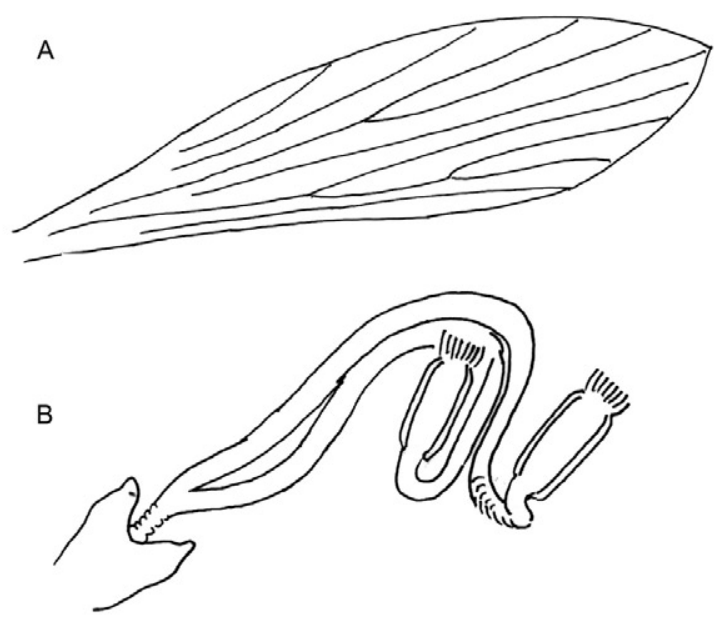

Fig. 3: female Sergentomyia (Parrotomyia) rectangulata. A: wing; B: spermathecae.

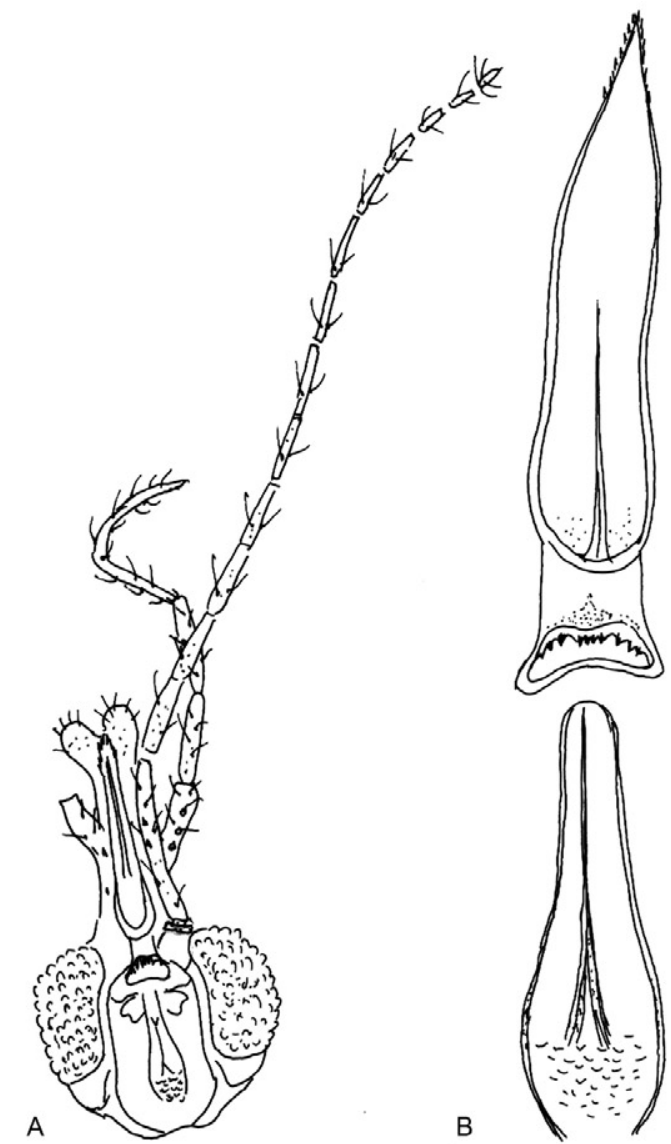

Fig. 4: male Sergentomyia (Parrotomyia) rectangulata. A: head; B: cibarium and pharynx.

Type - Holotype + , allotype $\precsim$ and paratypes $(3 \circ 5 \precsim)$ were collected using mechanical aspirators and torch lights. The holotype was collected in a termite mound from Mannadipet village on 7 February 2007. Of the three paratypes ( $($ ), one was collected in a tree hole on 22 April 2007 from the same village, located in Puduch-

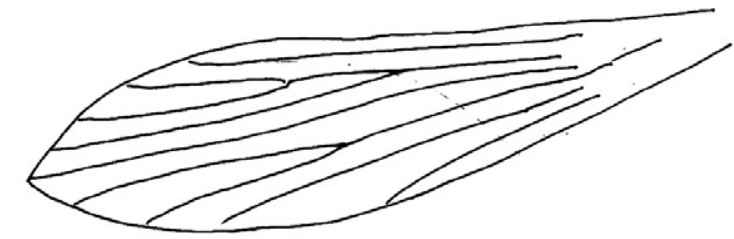

Fig. 5: male Sergentomyia (Parrotomyia) rectangulata (wing).

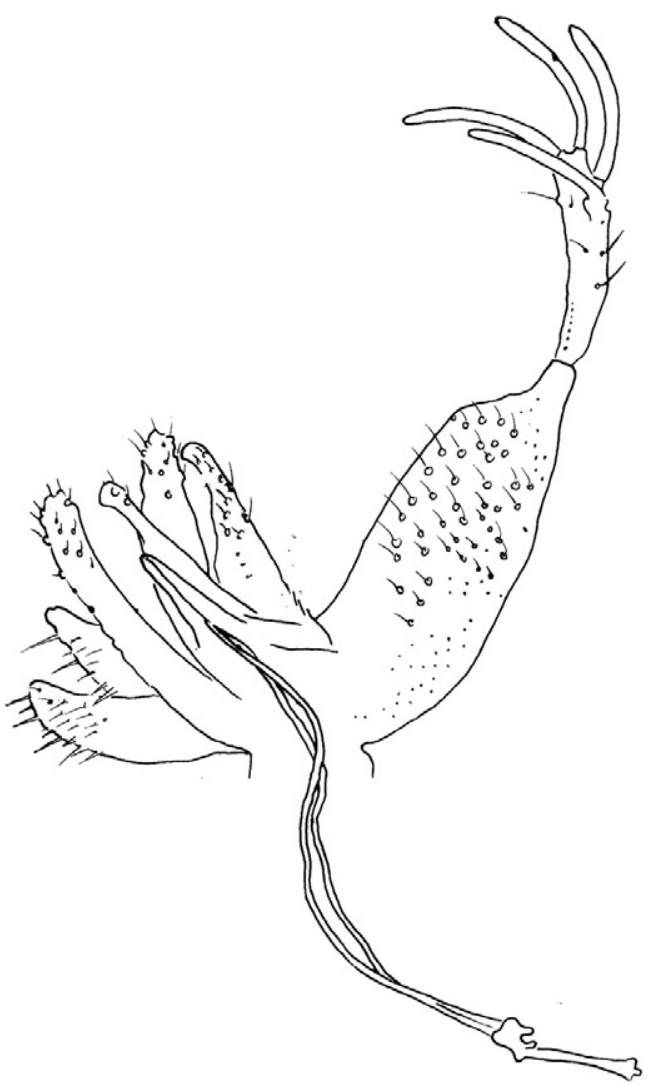

Fig. 6: male Sergentomyia (Parrotomyia) rectangulata (genitalia).

erry Union Territory and two were obtained in a cattle shed on 13 March 2008, from Avadi, Tamil Nadu. The allotype was collected in a termite mound from Mannadipet village on 22 April 2007. The paratypes $(\hat{)})$ were collected in termite mounds, one each on 3 January 2008 from Pillaiyarkuppam, on 12 September 2007, from Kalitheerthalkuppam and on 10 October 2007, from Muthirapalayam, situated in Puducherry, Puducherry Union Territory. The other two were obtained in a human dwelling, made of mud walls and a thatched roof on 24 July 2008, from Chengerla, Andhra Pradesh. Voucher specimens comprising both females (holotype and 3 paratypes) and males (allotype and 5 paratypes) were mounted separately on slides. All the materials are serially numbered and deposited in the museum, Vector Control Research Centre (Indian Council of Medical Research), Indira Nagar, Puducherry 605 006, India. 
The association between male and female specimens was made based on the number and shape of the cibarial teeth. Both sexes bear a row of comb-like parallel but irregular teeth, which are 12 in number. The name Sergentomyia rectangulata is given to this species based on the shape of the spermatheca, which is rectangular in shape when viewed in the sagittal plane.

\section{DISCUSSION}

The species described in the present communication has some features of the genus Sergentomyia such as the hind ends of abdominal tergites 2-6 with most hairs recumbent both in male and female specimens. In the male sandfly, the style of superior clasper has four spines, two of which are terminal, whereas the remaining ones are sub-terminal in position. The aedeagus is slender, triangular and narrowing gradually with a round end.

Cibarial armature has a row of comb-like parallel teeth with short points; pharynx is lamp-glass shaped; spermathecae are made of smooth capsules. These features permit the inclusion of the new species in the Parrotomyia subgenus.

Although the cibarial teeth are common in all the species described under the subgenus Parrotomyia, the cibarium does not have either a shallow notch in Sergentomyia (Par.) rectangulata sp. nov. as in Se. (Par.) shorttii or a deep notch as in Se. (Par.) babu and Se. (Par.) insularis. The new species of sandfly described in the study has a pigment patch, which is different from that of the other females already described. The pigment patch is yellow in colour with a thick dorsal process, whereas the dorsal process is bifid in Se. (Par.) barraudi. The cibarial teeth are not uniform in size in either sex. There are four median teeth, which are narrow, and four teeth on either side, which are broad. All the teeth are arranged in a convex row in the female, when seen from below. The number of teeth in Se. (Par.) rectangulata sp. nov. is 12, whereas the number of teeth is more than 20 in Se. (Par.) spinifaucis, Se. (Par.) mangana, Se. (Par.) queenslandi meridionalis, Se. (Par.) rudnicki, Se. (Par.) himalayensis, Se. (Par.) brevicaulis, Se. (Par.) africana magna, Se. (Par.) kauli, Se. (Par.) torrechantei, Se. (Par.) baghdadis, Se. (Par.) denticulata, Se. (Par) timorica, Se. (Par.) franciscana, Se. (Par.) dayapensis, Se. (Par.) bukidnonis and Se. (Par.) sogdiana and the number of cibarial teeth is less than 14 in Se. (Par.) brevinervis and Se. (Par.) bigtii. Though the number of teeth is the same as that of Se. (Par.) grekovi, the pharynx does not have spicules. Both Se. (Par.) modii and Se. (Par.) yoshimotoi, which have 16-18 teeth, differ from Se. (Par.) rectangulata $\mathrm{n}$. $\mathrm{sp}$. in having a protuberant knob structure, on the spermathecal head. In Se. (Par.) montana, the cibarial teeth are indistinct, in Se. (Par.) palestinensis the pharynx has pigmentation and in Se. (Par.) sumbarica, the teeth are arranged in a straight line. Female Se. (Par.) rectangulata nov. sp differs from Se. (Par.) shettyi, Se. (Par.) santokhi and Se. (Par.) yencaudensis by having an inverted funnel-shaped pigment patch with many black spine-like particles, which are concentrated towards the proximal and sparse towards the distal extremity. The spermathecae in Se. (Par.) rectangulata sp. nov. are smooth and the capsule is cylindrical, but when viewed in the sagittal plane, it is rectangle in shape. The spermathecae have secretary cells on the head, whereas in other species of the subgenus the spermathecae are elliptical or an elongated oval shape and the cibarial teeth are uniform in size and arranged in one or multiple rows. Male Se. (Par.) rectangulata sp. nov. differs from other related species by having a row of comb-like parallel but irregular cibarial teeth, visible from ventral side, which are 12 in number.

When examined for characteristic taxonomic features, sandflies of Sergentomyia (Par.) rectangulata sp. nov. differed from the other species described by Lewis (1978), Artemiev (1978) and Kalra and Bang (1988), which clearly suggests that the species described in this communication is distinct from other species already reported under this subgenus. Earlier reports on sandflies obtained from parts of the Indian sub-continent, (Kalra \& Bang 1988, Srinivasan et al. 1993, Ilango et al. 1994) indicate that Sergentomyia (Par.) rectangulata nov. sp is a new species found in southern India.

\section{ACKNOWLEDGEMENTS}

To Mr B Edwin, Mr SChandrasekar and Mr N Ramesh, Vector Control Research Centre, for technical assistance.

\section{REFERENCES}

Artemiev MM 1978. Sand flies (Diptera: Psychodidae: Phlebotominae) of Afghanistan, Marzinovoskyi Institute of Medical Parasitology and Tropical Medicine, Moscow, $83 \mathrm{pp}$.

ICZN - International Code of Zoological Nomenclature 1985. Adopted by the XX General Assembly of the International Union of Biological Sciences, British Museum Natural History, London, 338 pp.

Ilango K 2004. The legacy of Dr. Nelson Annandale and his contribution to the taxonomy of Phlebotomine sandfly species (Diptera: Psychodidae: Phlebotominae) transmitting leishmaniasis. Rec Zool Surv India 103: 115-121.

Ilango K, Dhanda V, Srinivasan R, Sadanand AV, Lane RP 1994. Phlebotomine sandflies (Diptera: Psychodidae) of Tamil Nadu and Pondicherry, southern India, in relation to visceral leishmaniasis. Ann Trop Med Parasitol 88: 413-431.

Kalra NL, Bang YH 1988. Manual on entomology in visceral leishmaniasis, World Health Organization, New Delhi, 88 pp.

Lewis DJ 1967. The Phlebotomine sand flies of West Pakistan (Diptera: Psychodidae). Bull British Museum (Natural History) Entomol 19: 1-57.

Lewis DJ 1978. The Phlebotomine sand flies of the Oriental region. Bull British Museum (Natural History) Entomol 37: 1-343.

Marcondes CB 2007. A proposal of generic and subgeneric abbreviations for Phlebotomine sand flies (Diptera: Psychodidae: Phlebotomidae) of the world. Entom News 118: 351-356.

Singh NS, Ipe M 2005. Description of two new species of Phlebotomus (Phlebotominae: Diptera) from Sikandra, U.P. Indian J Entomol 67: 144-149.

Sinton JA 1929. The identification and classification of the species of Phlebotomus, with some remarks on their geographical distribution in relation to disease, Trans, 7th Cong. Far East Assoc Trop Med 3: 172-193.

Srinivasan R, Panicker KN, Dhanda V 1993. Population dynamics of Phlebotomus papatasi (Diptera: Phlebotomidae) in Pondicherry, India. Acta Trop 54: 125-130. 